\title{
2 Iodinated disinfection byproducts: Formation and concerns
}

3 Cristina Postigo ${ }^{1,2}$, Bozo Zonja ${ }^{1}$

$4{ }^{1}$ Water and Soil Quality Research Group, Department of Environmental Chemistry, Institute of

5 Environmental Assessment and Water Research (IDAEA-CSIC), C/ Jordi Girona 18-26, 08034

6 Barcelona, Spain

$7 \quad{ }^{2}$ Department of Aquatic Sciences and Assessment, Swedish University of Agricultural Sciences,

8 Box 7050, SE-750 07 Uppsala, Sweden

9

\section{Abstract}

The list of iodinated disinfection byproducts (iodo-DBPs) includes some of the most genotoxic and cytotoxic DBPs discovered to date. Therefore, human exposure should be minimized by reducing their presence in drinking water. This manuscript reviews the main iodo-DBP formation pathways during water disinfection, with focus on the advances reported in the last two years. We discuss the effect of iodine sources other than iodine salts, e.g., iodinated contrast media and iodate, on iodo-DBP formation. In addition, we review the anthropogenic activities (like oil and gas extraction, dairy industry, seawater desalination or advanced oxidation treatments with persulfate) that may release iodo-DBPs to the aquatic environment or increase the potential of source waters to generate these compounds when disinfected.

Keywords: chloramination, iodinated contrast media, iodate, iodo-DBPs, iodide sources, permanganate, drinking water

\section{Introduction}

Chemical disinfection of source waters containing iodide may lead to the formation of iodine containing disinfection by-products (iodo-DBPs). Based on in vitro toxicity assay findings, iodinated and nitrogenous DBPs are considered as the most toxic DBPs in terms of genotoxicity and cytotoxicity in disinfected water $[1,2]$. Despite the facts that toxic evidence from in vivo assays or molecular epidemiology studies for these DBPs are still lacking and they are not regulated in drinking water, preventive actions call for minimizing their formation in drinking waters.

The existence of iodo-DBPs and in particular that of dichloroiodomethane in chlorinated water was for the first time discovered four decades ago [3]. Since then, and particularly within the last decade, iodo-DBPs have been reported to form after chemical disinfection of water with oxidizing agents other than chlorine, e.g., chloramine, chlorine dioxide [4], potassium permanganate [5], peracetic acid [6], ferrate [7] or iodine. Together with iodo-THMs, different chemical classes of iodo-DBP, e.g., iodo-acids, iodo-amides, iodo-aldehydes, and iodo-phenols, 
have been found in disinfected water [8-10]. The list of iodo-DBPs being discovered in disinfected waters is continuously expanding due to the increasing availability of advanced sensitive analytical technologies based on high-resolution mass spectrometry [11]. Different approaches have been proposed in the literature for new iodo-DBP identification [10, 12-16].

Similarly as for any other DBP, the extent of formation of iodo-DBPs during water disinfection depends on the organic and inorganic precursors (e.g., iodide and bromide) present in the source water. Additionally, their formation is determined by the type of disinfectant used and the conditions under which the disinfection process is carried out [17]. Most mechanistic studies conducted to elucidate iodo-DBP formation have used iodo-THMs as model compounds.

This review discusses the main formation pathways of iodo-DBPs during disinfection reactions and highlights the advances in this field, with focus on the research published in the last two years. It also tries to raise concern about those anthropogenic activities that may release iodo-DBPs to the aquatic environment or increase the iodo-DBP formation potential of drinking water sources.

\section{Formation mechanisms}

Oxidation of the iodide present in water during chemical disinfection processes usually leads to the formation of hypoiodous acid $(\mathrm{HOI})$ which may react with natural organic matter (NOM) to form iodo-DBPs or further oxidize to iodite and then to iodate (see Figure 1). The oxidation of $\mathrm{HOI}$ to iodate is favored among competing reactions in the presence of chlorine and ozone. The half-life of $\mathrm{HOl}$ is significantly higher under permanganate oxidation, and it is longest during chloramination (see Figure 1) $[18,19]$. Thus the potential for iodo-DBP formation is also expected to be highest during chloramine-based disinfection of iodidecontaining waters. This has been confirmed by both lab-controlled mechanistic studies and drinking water plant-scale monitoring studies [20]. However, reduced formation of iodo-DBPs during chloramination could be achieved if water is previously preoxidized with chlorine, permanganate at $\mathrm{pH}<6$ or $>8$ [19], ferrate [7] or ozone [21]. During this preoxidation stage, iodide gets partially removed from the system by its rapid oxidation to iodate.

Several works have focused on investigating the effects of chlorine or chloraminebased disinfection conditions on iodo-DBP formation. They have covered various i) water $\mathrm{pH}$ values, ii) disinfectant doses and contact times, iii) types of NOM (e.g., effluent wastewater, standard fulvic and humic substances, and drinking water sources: Llobregat River (Spain), Aliakmon River (Greece) and Miyun Reservoir (China)), iv) levels of NOM and iodide, or v) bromide/iodide and iodide/DOC concentration ratios [17, 20,22-24]. Overall, findings indicate that iodide incorporation into NOM is enhanced at increasing concentrations of iodide in water, and reduced at increasing bromide and DOC concentrations. However, such conclusions were mostly drawn from lab-controlled reactions with simulated water and in some cases, after addition of high concentrations of iodide into the source water. Thus, they need to be confirmed in real water at plant scale. Furthermore, most mechanistic studies were focused only on few DBPs (e.g., iodo-THMs, iodo-acids, iodoacetaldehyde, and iodo-haloacetamides) that represent a very small part of the total organic iodine formed. 


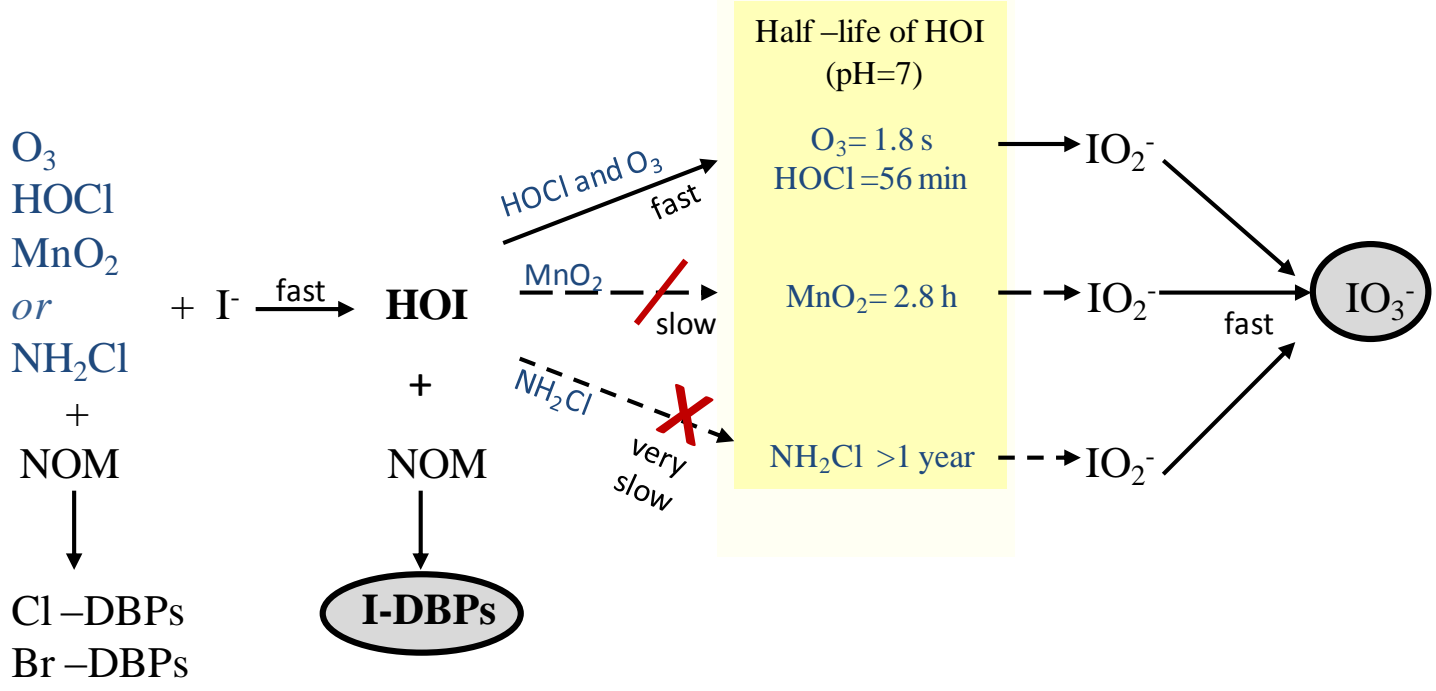

80

Figure 1. Reactivity of iodide and $\mathrm{HOI}$ in the presence of ozone, free chlorine, permanganate, and chloramine.

Although little is still known about specific iodo-DBP precursors, experiments with simulated drinking water containing Suwannee River fulvic acid (SRFA) and $200 \mu \mathrm{g} / \mathrm{L}$ of iodide showed that high aromaticity molecules seem to be highly reactive to chloramine oxidation to form iodo-DBPs [16]. However, the formation of specific iodo-DBP classes, i.e., iodo-haloacetic acids and iodo-THMs, has been associated to NOM fractions with low aromaticity $[17,20]$. This was shown in experiments with simulated water containing Suwannee River and Nordic Lake NOM and a wide range of iodide levels $(50 \mu \mathrm{g} / \mathrm{L}$ to $38 \mathrm{mg} / \mathrm{L})[17,20]$ and by chloramination of model compounds known to be present in NOM and to react with free halogens, i.e., several amino acids, carboxylic acids and aromatic compounds [17]. The highest iodo-DBP yields (up to $0.5 \%)$ were provided by citric acid, L-aspartic acid, and pyruvic acid [17].

Tyrosyl dipeptides were also recently identified as iodo-DBP precursors. lodine substituted tyrosyl dipeptide products, formed after iodine substitution on the 3- or 3,5-positions of the tyrosyl-phenol ring were discovered in lab-controlled chloramination reactions of seven tyrosyl dipeptides. Four of these iodinated dipeptides (3-iodo- and 3,5-di-iodo-Tyr-Ala and 3-iodo- and 3,5-di-iodo-Tyr-Gly), and their corresponding precursors (tyrosylalanine and tyrosylglycine), were found to be present in real chloraminated tap water (see Figure 2) [25].

lodine incorporation during the reaction of $\mathrm{HOI}$ with (hydroxyl)phenolic compounds and Nordic Lake and Pony Lake fulvic acid extracts can occur through electrophilic aromatic substitution and/or electron transfer. The extent of these processes depends on the number and relative position of the hydroxyl moieties on the phenolic compounds [26]. 


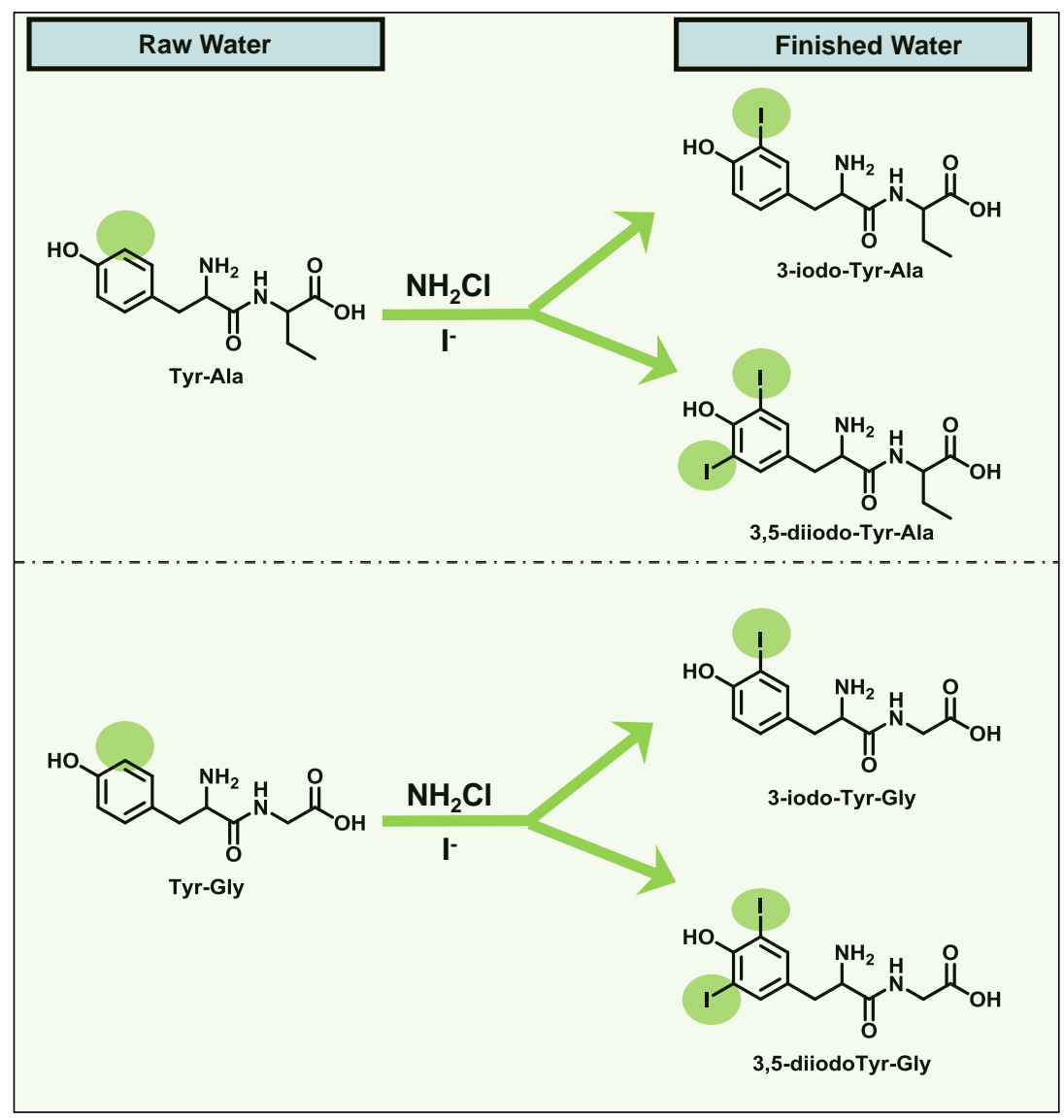

Figure 2. lodine substituted tyrosyl dipeptide compounds found in chloraminated tap water.

\subsection{Reactivity of additional iodine sources in water - effects on iodo-DBP formation}


Besides natural iodide salts, iodinated X-ray contrast media (ICM) used for medical imaging of soft tissues have been discovered as a relevant source of iodine that leads to the formation of iodo-DBPs during chlorination and chloramination of drinking water sources. Since the first work carried out on this topic by Duirk et al. [31], several studies have confirmed this [22, 32-36]. Of all ICM tested (i.e., diatrizoate, iodixanol, iohexol, iomeprol, iopamidol, and iopromide), iopamidol seems to be the most reactive compound. The highest concentrations of iodo-THMs and iodo-acids were consistently found in chlorinated iopamidol containing waters (intake of three water treatment plants in Ohio [31, 36], and one in Shanghai [33]). In the absence of NOM, only a small percentage of the initial iopamidol concentration $(<2 \%$ after $24 \mathrm{~h}$ ) is actually transformed into known low molecular weight iodo-DBPs [32]. The degradation pathway and kinetics of iopamidol during chlorination and chloramination as well as the high-molecular weight DBPs formed during these processes have been already described in the literature $[32,35]$. However, such studies were performed in purified water and the effects of NOM were not investigated.

lopamidol deiodination, and hence, iodo-DBP formation, also can also occur under Ferrate $(\mathrm{Fe}(\mathrm{VI}))$ oxidation [37] and in the presence of zerovalent iron [38]. In the case of $\mathrm{Fe}^{0}$, the reaction was enhanced in acidic conditions and in the presence of specific anions $\left(\mathrm{SO}_{4}{ }^{-2}\right.$ and $\mathrm{Cl}-$ ) and monochloramine [38].

The release of iodide from ICM after UV irradiation and the effects on iodo-DBP formation during subsequent chemical oxidation has been studied in several occasions [39-41]. lodide release from five ICM increased at increasing UV doses and decreased at increasing Suwannee River NOM concentrations [39]. However, the type of NOM (up to seven types of NOM tested with specific UV absorbance (SUVA) values ranging 1.6-4.45) did not have a significant impact on the degradation of iopromide, the formation of iodo-DBPs or the iodine speciation. For all ICM, higher concentrations of iodo-DBPs were formed during $\mathrm{UV} / \mathrm{NH}_{2} \mathrm{Cl}$ than with $\mathrm{UV} / \mathrm{HOCl}$. While iodo-DBP formation was reduced at increasing chlorine doses because $\mathrm{HOI}$ was rapidly converted to iodate, in the case of $\mathrm{UV} / \mathrm{NH}_{2} \mathrm{Cl}$, the chloramine dose did not have any effect on the iodo-DBP levels formed [39]. Additionally, the release of iodide from ICM was reported under natural sunlight irradiation, with the subsequent formation of the deiodinated transformation products (TPs) [42].

\subsection{2. lodate}

lodate was always considered an innocuous and stable sink for iodine. However, Tian et alreported in a recent work that iodate can significantly photoreduce into iodide by UV at neutral $\mathrm{pH}$ [43]. Moreover, the photodegradation rate of iodate could be enhanced in the presence of NOM (Huangpu River NOM, and SRFA). Thus, the UV pretreatment of iodatecontaining water, especially before chloramination, may enhance iodo-DBP formation.

lodate is also converted into iodide after its reduction by zerovalent iron. This process may occur in unlined cast iron pipes, widely used in drinking water distribution networks. Higher zerovalent iron dosages led to increasing formation of iodo-THMs in chloraminated waters 
without any other iodine source but iodate. The presence of goethite and hematite in the system enhanced iodo-THM formation [44].

\section{Sensitive scenarios}

lodo-DBPs are typically analyzed in drinking water. However, their formation may also be relevant in industries where iodine or iodine-based disinfectants are used for sanitization, such as the dairy industry. Wastewaters from milk and cheese processing facilities contained up to 6 $\mu \mathrm{g} / \mathrm{L}$ of iodo-THMs. The contribution of iodo-THMs to total trihalomethane loads ranged 0 $100 \%$. Diluted concentrations of iodo-THMs were found in surface waters impacted by these facilities. This finding confirms dairies as a source of these toxic compounds to receiving water bodies [45].

Hydraulic fracturing flow-back fluids and oil and gas wastewater from conventional oil and gas operations contain high levels of halides, with iodide concentrations reaching up to 28 $\mathrm{mg} / \mathrm{L}$ [46]. Thus, their eventual spill or discharge into drinking water sources may result in an enhanced potential of these waters to form iodo-DBPs during disinfection treatments. Besides representing a source of iodide into the aquatic environment, the flow-back water may even contain many iodo-organic compounds, including iodo-acids, whose origin is still not clear (biotic or abiotic reactions, shale origin or fracking additives) [14, 47]. Oil and gas produced wastewater also showed the potential to form a wide spectrum of iodo-phenols during chloramination reactions. Methylphenol and dimethylphenol, of geogenic origin, were identified as the main precursors of the iodo-phenols formed [15].

Desalinated seawater, a water resource increasingly being used worldwide to fulfill drinking water demands, may contain considerable amounts of bromide and iodide. Residual iodide levels may be more relevant in reverse osmosis-based desalination plants than in thermal-based desalination plants. However, and in spite of the fact that chemical disinfection is usually conducted during the desalination process, DBP formation in desalinated water is not relevant due to its low NOM content. The risk for iodo-DBP formation arises when desalinated water is blended with the final product of a conventional drinking water treatment plant since NOM is introduced in the system for reaction. Likewise, high risk of iodo-DBP formation potentially exists if the desalinized water gets into contact with the biofilm which is present along the drinking water distribution system network. Research needs in this field proposed by Kim et al. [48] have been hardly covered to date.

Advanced oxidation processes (AOPs) using persulfate or peroxymonosulfate have shown applicability in remediation of soil/groundwater pollution. Contrary to hydroxyl radicals, the sulfate radical $\left(\mathrm{SO}_{4}{ }^{-}\right)$generated during these processes are preferentially scavenged by halides than by NOM. As a result halogen radical species and free halogens are formed, and consequently iodo-DBPs, like iodo-di-haloacetamides [49] or iodoform and iodoacids in a carbon nanotube activated persulfate oxidation system [50]. Considerable amounts of TOI were also reported to get formed after peroxymonosulfate oxidation of iodide in Suwannee River NOM solutions [51]. Recently, Wang et al reported the formation of iodoform and iodoacetic acids from phenol (the model compound used to mimic reactivity of dissolved NOM in the study) in a heat activated persulfate system [52]. lodophenols were also detected as 
intermediates during the process. However, all iodo-DBPs formed were found to further oxidate to iodate in excess of sulfate radicals.

\section{Future research needs}

Known iodo-DBPs constitute a small part of TOI in water. Thus, formation mechanisms of iodo-DBPs should be investigated preferably taking also into account the unknown fraction of TOI. For this, reliable and novel methodologies to measure TOI are needed. Some works have been focused recently on this aspect $[53,54]$. Furthermore, new analytical approaches and methodologies are needed to discover relevant iodo-DBPs in the DBP mixture. Current advances on analytical technology, e.g., development and commercialization of benchtop easy-to-operate sensitive high-resolution mass spectrometry instruments, may contribute to overcoming this analytical challenge.

Formation mechanisms of iodo-DBPs need to be further investigated at environmental conditions, and preferably at industrial plant scale so that findings can be easily applied to improve drinking water quality. Exhaustive characterization of the drinking water source in each case is needed so that results can be scaled up to different treatment plants. The formation of iodo-DBPs in reclaimed water should be also assessed when a chlorine-based disinfection treatment is used for water regeneration. Formation mechanisms of iodo-DBPs in wastewater are expected to differ from those observed in drinking water due to the different nature of the NOM present in these matrices.

Despite the fact that concentrations of individual iodo-DBPs in drinking water are usually much lower in mass than those measured for individual regulated trihalomethanes and haloacetic acids ( $<1 \mathrm{ppb}$ vs few to tens of $\mathrm{ppb}$ ), their presence may still represent a potential risk for human health since they have exhibited a comparatively higher toxicity than their bromine and chlorine analogues in different in vitro studies. Thus minimization of iodoDBP exposure and protection of human and ecosystems health calls for adopting adequate measures to minimize iodine sources and iodo-DBP release into surface waters and to remove iodo-DBP precursors in drinking water sources before their disinfection.

\section{Acknowledgements}

C. Postigo acknowledges the financial support by Fundación General CSIC (Spanish ComFuturo Programme). This work was financially supported by the Government of Catalonia (Consolidated Research Groups 2017 SGR 1404-Water and Soil Quality Unit) and by the Swedish University of Agricultural Sciences through the "August T Larsson Guest Researcher Programme".

\section{References}

1. Richardson, S.D., et al., Occurrence, genotoxicity, and carcinogenicity of regulated and emerging disinfection by-products in drinking water: A review and roadmap for research. Mutation Research/Reviews in Mutation Research, 2007. 636(1): p. 178-242. ** This manuscript is a comprehensive review of the data available regarding the occurrence and toxicity of 85 DBPs and the gaps of knowledge in this field of research. 
2. Cortés, C. and R. Marcos, Genotoxicity of disinfection byproducts and disinfected waters: A review of recent literature. Mutation Research/Genetic Toxicology and Environmental Mutagenesis, 2018. 831: p. 1-12.

3. Thomas, R. and M. Weisner, in Thomas, R.F., Weisner M.J., Brass HJ (1980) The fifth trihalomethane: dichloroiodomethane. Its stability and occurrence in chlorinated drinking water. In: Jolley RL, Brungs WA, Cumming RB, Jacobs VA (eds) Water chlorination: environmental impact and health effects, vol 3. Ann Arbor Science, Ann Arbor, MI, pp 161-168.

4. Ye, T., et al., Formation of iodinated disinfection by-products during oxidation of iodidecontaining waters with chlorine dioxide. Water Research, 2013. 47(9): p. 3006-3014.

5. Ye, T., et al., Formation of iodinated disinfection by-products during oxidation of iodidecontaining water with potassium permanganate. Journal of Hazardous Materials, 2012. 241-242: p. 348-354.

6. Xue, R., et al., Evaluation of thirteen haloacetic acids and ten trihalomethanes formation by peracetic acid and chlorine drinking water disinfection. Chemosphere, 2017. 189: p. 349-356.

7. Zhang, M.S., et al., Formation of iodinated trihalomethanes after ferrate pre-oxidation during chlorination and chloramination of iodide-containing water. Journal of the Taiwan Institute of Chemical Engineers, 2016. 60: p. 453-459.

8. Richardson, S.D. and C. Postigo, Formation of DBPs: State of the Science, in ACS Symposium Series. 2015. p. 189-214.

**Authors review the formation mechanisms of DBPs during disinfection of water.

9. Pan, Y., et al., Formation and occurrence of new polar iodinated disinfection byproducts in drinking water. Chemosphere, 2016. 144: p. 2312-2320.

10. Gong, T. and X. Zhang, Detection, identification and formation of new iodinated disinfection byproducts in chlorinated saline wastewater effluents. Water Research, 2015. 68: p. 77-86.

11. Richardson, S.D. and C. Postigo, Liquid Chromatography-Mass Spectrometry of Emerging Disinfection By-products, in Comprehensive Analytical Chemistry. 2018. p. 267-295.

12. Gallidabino, M.D., et al., Suspect screening of halogenated carboxylic acids in drinking water using ion exchange chromatography - High resolution (Orbitrap) mass spectrometry (IC-HRMS). Talanta, 2018. 178: p. 57-68.

13. Postigo, C., et al., Characterization of iodinated disinfection by-products in chlorinated and chloraminated waters using Orbitrap based gas chromatography-mass spectrometry. Analytical and Bioanalytical Chemistry, 2016. 408(13): p. 3401-3411.

14. Luek, J.L., et al., Halogenated Organic Compounds Identified in Hydraulic Fracturing Wastewaters Using Ultrahigh Resolution Mass Spectrometry. Environmental Science and Technology, 2017. 51(10): p. 5377-5385.

15. Liberatore, H.K., et al., Identification and Comparative Mammalian Cell Cytotoxicity of New lodo-Phenolic Disinfection Byproducts in Chloraminated Oil and Gas Wastewaters. Environmental Science and Technology Letters, 2017. 4(11): p. 475-480.

16. Wang, X., et al., Characterization of unknown iodinated disinfection byproducts during chlorination/chloramination using ultrahigh resolution mass spectrometry. Science of the Total Environment, 2016. 554-555: p. 83-88.

17. Liu, S., et al., Formation of iodo-trihalomethanes, iodo-acetic acids, and iodoacetamides during chloramination of iodide-containing waters: Factors influencing formation and reaction pathways. Journal of Hazardous Materials, 2017. 321: p. 28-36.

18. Bichsel, Y. and U. Von Gunten, Oxidation of iodide and hypoiodous acid in the disinfection of natural waters. Environmental Science and Technology, 1999. 33(22): p. 4040-4045. 
* Authors evaluated the sink for iodine during ozonation, chlorination, and chloramination of natural waters by determining the kinetics of several oxidation reactions of hypoiodous acid, and discusses its relevance for the formation of iodoorganic compounds.

19. Zhao, X., et al., Kinetic and Mechanistic Aspects of the Reactions of lodide and Hypoiodous Acid with Permanganate: Oxidation and Disproportionation. Environmental Science and Technology, 2016. 50(8): p. 4358-4365.

* Authors studied the oxidation kinetics of iodide and $\mathrm{HOI}$ with potassium permanganate in the $\mathrm{pH}$ range of 5-10

20. Postigo, C., S.D. Richardson, and D. Barceló, Formation of iodo-trihalomethanes, iodohaloacetic acids, and haloacetaldehydes during chlorination and chloramination of iodine containing waters in laboratory controlled reactions. Journal of environmental sciences (China), 2017. 58: p. 127-134.

21. Allard, S., et al., Ozonation of iodide-containing waters: Selective oxidation of iodide to iodate with simultaneous minimization of bromate and I-THMs. Water Research, 2013. 47(6): p. 1953-1960.

22. Pantelaki, I. and D. Voutsa, Formation of iodinated THMs during chlorination of water and wastewater in the presence of different iodine sources. Science of The Total Environment, 2018. 613-614: p. 389-397.

23. Liu, Z., et al., Formation of iodinated trihalomethanes during breakpoint chlorination of iodide-containing water. Journal of Hazardous Materials, 2018. 353: p. 505-513.

24. Zhang, J., et al., Role of NOM molecular size on iodo-trihalomethane formation during chlorination and chloramination. Water Research, 2016. 102: p. 533-541.

25. Huang, G., et al., Formation and Occurrence of lodinated Tyrosyl Dipeptides in Disinfected Drinking Water. Environmental Science and Technology, 2018. 52(7): p. 4218-4226.

26. Zhao, X., J. Ma, and U. von Gunten, Reactions of hypoiodous acid with model compounds and the formation of iodoform in absence/presence of permanganate. Water Research, 2017. 119: p. 126-135.

27. Zhu, X. and X. Zhang, Modeling the formation of $\mathrm{TOCl}, \mathrm{TOBr}$ and TOI during chlor(am)ination of drinking water. Water Research, 2016. 96: p. 166-176.

28. Gong, T., et al., Transformation among Aromatic lodinated Disinfection Byproducts in the Presence of Monochloramine: From Monoiodophenol to Triiodophenol and Diiodonitrophenol. Environmental Science and Technology, 2017. 51(18): p. 1056210571.

29. Abusallout, I. and G. Hua, Photolytic dehalogenation of disinfection byproducts in water by natural sunlight irradiation. Chemosphere, 2016. 159: p. 184-192.

30. Wang, A.Q., et al., Kinetics and modeling of iodoform degradation during UV/chlorine advanced oxidation process. Chemical Engineering Journal, 2017. 323: p. 312-319.

31. Duirk, S.E., et al., Formation of toxic iodinated disinfection by-products from compounds used in medical imaging. Environmental Science and Technology, 2011. 45(16): p. 6845-6854.

*This is the first study that evaluated X-Ray contrast media as iodine sources and the potential implications for iodo-DBP formation.

32. Wendel, F.M., et al., Transformation of iopamidol during chlorination. Environmental Science and Technology, 2014. 48(21): p. 12689-12697. 
33. Ye, T., et al., Comparison of iodinated trihalomethanes formation during aqueous chlor(am)ination of different iodinated $X$-ray contrast media compounds in the presence of natural organic matter. Water Research, 2014. 66: p. 390-398.

34. Jeong, C.H., et al., The impact of iodinated $X$-ray contrast agents on formation and toxicity of disinfection by-products in drinking water. Journal of Environmental Sciences, 2017. 58: p. 173-182.

35. Tian, F.X., et al., Chlor(am)ination of iopamidol: Kinetics, pathways and disinfection byproducts formation. Chemosphere, 2017. 184: p. 489-497.

36. Ackerson, N.O.B., et al., Formation of DBPs and halogen-specific TOX in the presence of iopamidol and chlorinated oxidants. Chemosphere, 2018. 202: p. 349-357.

37. Dong, H., et al., Oxidation of iopamidol with ferrate (Fe(VI)): Kinetics and formation of toxic iodinated disinfection by-products. Water Research, 2018. 130: p. 200-207.

38. Dong, H., et al., Deiodination of iopamidol by zero valent iron (ZVI) enhances formation of iodinated disinfection by-products during chloramination. Water Research, 2018. 129: p. 319-326.

39. Allard, S., et al., Photodecomposition of iodinated contrast media and subsequent formation of toxic iodinated moieties during final disinfection with chlorinated oxidants. Water Research, 2016. 103: p. 453-461.

40. Wang, Z., et al., Degradation of iohexol by UV/chlorine process and formation of iodinated trihalomethanes during post-chlorination. Chemical Engineering Journal, 2016. 283: p. 1090-1096.

41. Tian, F.X., et al., Photodegradation kinetics of iopamidol by UV irradiation and enhanced formation of iodinated disinfection by-products in sequential oxidation processes. Water Research, 2014. 58: p. 198-208.

42. Zonja, B., et al., LC-HRMS Suspect Screening for Detection-Based Prioritization of lodinated Contrast Media Photodegradates in Surface Waters. Environmental Science \& Technology, 2015. 49(6): p. 3464-3472.

43. Tian, F.X., et al., Phototransformation of iodate by UV irradiation: Kinetics and iodinated trihalomethane formation during subsequent chlor(am)ination. Journal of Hazardous Materials, 2017. 326: p. 138-144.

44. Xia, Y., et al., lodinated trihalomethane formation during chloramination of iodatecontaining waters in the presence of zero valent iron. Water Research, 2017. 124: $p$. 219-226.

45. Hladik, M.L., et al., Dairy-Impacted Wastewater Is a Source of lodinated Disinfection Byproducts in the Environment. Environmental Science and Technology Letters, 2016. 3(5): p. 190-193.

*Authors investigated dairy industry as a potential source of iodo-DBPs into the environment

46. Harkness, J.S., et al., lodide, bromide, and ammonium in hydraulic fracturing and oil and gas wastewaters: Environmental implications. Environmental Science and Technology, 2015. 49(3): p. 1955-1963.

47. Hladik, M.L., M.J. Focazio, and M. Engle, Discharges of produced waters from oil and gas extraction via wastewater treatment plants are sources of disinfection by-products to receiving streams. Science of the Total Environment, 2014. 466-467: p. 1085-1083.

48. Kim, D., G.L. Amy, and T. Karanfil, Disinfection by-product formation during seawater desalination: A review. Water Research, 2015. 81: p. 343-355.

49. Chu, W., et al., Water temperature significantly impacts the formation of iodinated haloacetamides during persulfate oxidation. Water Research, 2016. 98: p. 47-55.

50. Guan, C., et al., Transformation of lodide by Carbon Nanotube Activated Peroxydisulfate and Formation of lodoorganic Compounds in the Presence of Natural Organic Matter. Environmental Science \& Technology, 2017. 51(1): p. 479-487. 
51. Li, J., et al., Kinetics of Oxidation of lodide (I-) and Hypoiodous Acid (HOI) by Peroxymonosulfate (PMS) and Formation of lodinated Products in the PMS/I-/NOM System. Environmental Science \& Technology Letters, 2017. 4(2): p. 76-82.

52. Wang, L., et al., Transformation of iodide and formation of iodinated by-products in heat activated persulfate oxidation process. Chemosphere, 2017. 181: p. 400-408.

53. Kinani, A., et al., Determination of adsorbable organic halogens in surface water samples by combustion-microcoulometry versus combustion-ion chromatography titration. Journal of Chromatography A, 2018. 1539: p. 41-52.

54. Sayess, R. and D.A. Reckhow, An improved method for total organic iodine in drinking water. Water Research, 2017. 108: p. 250-259. 